\title{
HISTORIA DE UNA COMA. GADAMER Y EL SENTIDO DEL SER*
}

\author{
Gianni VATTIMO \\ Universidad de Turin
}

\begin{abstract}
RESUMEN. A partir de la doble posibilidad de traducir en las lenguas románicas la expresión gadameriana «Sein, das verrtanden werden kann, ist Sprache* como " $E l$ ser, que puede ser comprendido, es lenguajen o como «El ser que puede ser comprendido es lenguajen, se consideran las importantes repercusiones ontológicas que tendría una interpretación más moderada (y más habitual) de ese enunciado (la primera exhibida), o una lectura más radical y nihilista (la que aquí se defiende) del mismo (la segunda traducción propuesta). Se intenta mostrar que una correcta comprensión de la diferencia ontológica abogaría por esta segunda posibilidad, por cuanto no son los entes los que se reducen, idealistamente, a mero lenguaje, sino el ser. lo cual evita cualquier residuo «metafisico» o «positivista* que, dando por supuesto que este último se reduce a los primeros, aluda aún a cierto usem (o, en esta perspectiva, «entes") que está más allá (y aún por descubrir) del lenguaje.
\end{abstract}

Tiene razón Richard Bernstein cuando afirma que «si uno se toma en serio a Gadamer y desarrolla sus tesis hasta el final [press his own claims], termina por sobrepasar la hermenéutica filosófica»" Este camino "más allá de la hermenéutica gadameriana -que, sin embargo, solamente podremos descubrir después

* Traducción a cargo de Miguel Ángel Quintana Paz a partir del artículo original francés: G. Vattimo, "Histoire d'une virgule. Gadamer et le sens de l'êtrew, Revue Internationale de Philosopbie, n. 213 (2000), pp. 499-513. Quiero agradecer a Ana Isabel Roquena Benito sus urilisimas ayudas para cal tarea, que, por lo demás, ha sido posible gracias a una beca postdoctoral concedida por el Eusko Jaurlarizza-Gobierno Vasco para la investigación en la Facoltà di Lettere e Filosofia de Turín (Italia) entre 2002 y 2004, bajo la dirección del propio Gianni Vattimo.

${ }^{1}$ R. J. BERNSTEIN, Bgond Objectivism and Relativism: Science, Hermeneutio, and Procais, Oxfond, Basil Blackwell, 1983, p. 150. 
de habernos tomado muy en serio a este autor, y tras haber seguido con radicalidad, hasta el final, sus propias indicaciones - podría trazarse asimismo a partir de un aspecto tan marginal como una coma. Es también y sobre todo a partir de ciertas consideraciones sobre el problema de una coma que la radicalización ontológica y nihilista de la hermenéutica puede comenzar y, de hecho, es así que esta, al menos en mi caso, ha comenzado: pues tal radicalización representa en mi opinión un despliegue legítimo (y posiblemente el despliegue legítimo e incluso ineludible) de la filosofía gadameriana.

El enunciado «Sein, das verstanden werden kann, ist Sprache» ${ }^{2}$ me supuso numerosos problemas cuando hube de traducirlo al italiano (es preciso recordar aquí que la traducción italiana de Verdad y Método fue la primera entre las múltiples traducciones que después vinieron a sumársele). Mientras que, por cuanto yo sé, el alemán no ofrece tal distinción, en italiano - y creo que igualmente en francés ${ }^{3}$ - el sentido del enunciado cambia profundamente según se introduzca o no una coma después de Sein y, por consiguiente, después de kann. Estas comas existen en la versión alemana, pero resulta plausible suponer que sin el valor "ontológico" que han adquirido luego en sus traducciones. Si digo "l'essere che pù̀ essere compreso è linguaggion (el ser que se puede comprender es lenguaje), estoy afirmando algo relativamente inofensivo: identifico el campo de los entes que se ofrecen a la comprensión con el del lenguaje; si en cambio digo: "l'essere, che pud essere compreso, è linguaggio» (el ser, que se puede comprender, es

${ }^{2}$ H.-G. GADAMER, Gesammelte Werke, vol. 1 (Hermeneutik I: Wahrheit und Methode), Tubinga, Mohr, 1986, p. 478, en cursiva en el original (versión española: «El ser que puede ser comprendido es lenguajen, en H.-G. GADAmer, Verdad y método I, trad. de A. Agud y R. de Agapito, Salamanca, Sígueme, 1977, p. 567; citamos, a partir de ahora, esta versión como VM]. [Nota del traductor. Como se verá, Agud y De Agapito optan en esta su traducción de la frase que nos ocupa precisamente por la alternativa contraria a aquella que Vattimo defenderá en este artículo; esa opción vattimiana podría reformularse en castellano, si seguimos la opción verbal —con forma pasiva no refleja- de estos dos traductores como «El ser, que puede ser comprendido, es lenguajen, de modo que la hacemos constar aquí como posibilidad que, al menos en principio, también se halla encerrada en la proposición gadameriana que Vattimo aquí reporta].

${ }^{3}$ Al tratar de verter al español la mentada frase alemana acaece el mismo fenómeno que Vattimo detecta en las también románicas versiones italiana y francesa: pues en todas ellas resulta ineludible tener que optar (cosa que no ocurre en la lengua teutona) entre un "que" calificativo (con coma delante) y un "que" especificativo (sin tal coma); es por lo tanto plenamente aplicable a nuestro idioma cuanto se dice en el cuerpo del texto a partir de ahora sobre estas otras dos lenguas latinas, la itálica y la gala. [Nota del traductor]. 
lenguaje), entonces esa expresión en italiano significa: el ser es lenguaje y, además, puede comprenderse.

Gadamer nunca se pronunció explícitamente a favor de esta segunda lectura, fuerte, de su tesis; y, según varios intérpretes, algunas de sus propias afirmaciones la excluyen. Temo que estos intérpretes tengan en el fondo razón, si bien los textos gadamerianos que aducen en su apoyo no parezcan tener un valor probatorio tan definitivo como el que ellos suponen. Por ejemplo, la afirmación gadameriana según la cual «el principio del carácter lingüístico de la comprensión no significa que toda nuestra experiencia del mundo únicamente se dé como lenguaje hablado y en el lenguaje hablado", ¿tiene realmente el sentido, como sostiene un tanto apresuradamente J. Grondin, de dar por zanjada esta cuestión ${ }^{4}$ ? El hecho general, sobre el cual se hace asimismo hincapié, de que la experiencia del mundo sea también la búsqueda de la palabra "justa" (para "cosas" que se darían, pues, antes de ser nombradas); y el hecho de que todo decir esté por su parte rodeado de un halo de lo-no-dicho (porque usiempre hay un querer decir, una intención que va más allá, o al lado, de lo que ha sido captado en el lenguaje y en palabras, y que sale al encuentro del otro. Una búsqueda jamás terminada de la palabra justa: he aquí lo que determina la vida real y la esencia del lenguajen ${ }^{5}$ ), no se contraponen al carácter lingüístico de toda experiencia: lo cual debería servir entonces como prueba del hecho de que para Gadamer las cosas no lle-

${ }^{4}$ J. Grondin, L'universalité de l'herméneutique, París, P.U.F., 1993, p. 184. La cita previa es de H.-G. GADAMER, Gesammelte Werke, vol. 2 (Hermeneutik II: Wabrheit und Methode), Tubinga, Mohr, 1986, p. 496 (versión española: H.-G. GADAMER, Verdad y método, II, trad. de M. Olasagasti, Salamanca, Sígueme, p. 391-392; citamos, a partir de ahora, esta versión como VM-II). [Nota del traductor. La traducción que figura en el cuerpo del texto trata de reflejar el tipo de traducción que hace a partir del alemán el propio Vattimo; sin embargo, la citada versión española de M. Olasagasti vierte en nuestra lengua esta frase con sustanciales diferencias, que reproducimos aqui: «La lingüisticidad fundamental de la comprensión no significa obviamente que la experiencia del mundo se efectúe como lenguaje y en el lenguaje exclusivamente". A fin de contrastar ambas posibilidades, acaso no sea fútil reportar aquí literalmente la expresión original tudesca de Gadamer en el pasaje ya referido: «Natuirlich kann mit der prinzipiellen Sprachlichkeit des Verstehens nicht gemeint sein, dass alle Welterfahrung sich nur als Sprechen und im Sprechen vollzöge»].

5 J. Grondin, L'universalité de l'herméneutique, op. cit., p. 190. Para la cita gadameriana, Grondin nos remite a H.-G. GADAMER, "Grenzen der Sprache", en W. BOHME (ed.), Evolution und Sprache: über Entstehung und Wesen der Sprache (Herrenalber Texte, 66), Karlsruhe, Evangelische Akademie Baden, 1985, p. 99. [Nota del traductor: completamos y corregimos aquí diversas erratas de la referencia del texto gadameriano que Vattimo proporciona en su artículo original]. 
gan al ser sino cuando vienen al lenguaje. Si se presta atención, la preocupación —de intérpretes como los ya nombrados, y probablemente de Gadamer mismo- por no identificar todo el ser con el lenguaje refleja una dificultad real, una ambigüedad o residuo metafísico no superado en lo que respecta a la ontología: pues sólo en el caso de que se siguiese pensando que el ser del mundo es lo mismo, básicamente, que los objetos (en tanto que estos se dan en el espaciotiempo y mediante su propia presencia), parecería escandalosa la lectura ontológicamente más radical de esa identidad del ser con el lenguaje. Gadamer se preocupa con razón de evitar que se le lea como si fuese un idealista empírico, lo cual resultaría inevitable si hubiese aceptado identificar el ser, así entendido, con el lenguaje en efecto dado, hablado, o simplemente con sus eventuales estructuras profundas y permanentes, chomskianas.

El hecho es que, tanto para sus intérpretes como para el propio Gadamer, el desarrollo de la hermenéutica, más allá de la formulación explícita y por otra parte clásica que él mismo nos aportó, se ha efectuado hasta ahora primordialmente en el sentido de una uurbanización" pragmatista de su pensamiento. Para convencerse de ello, basta con atender a la literatura secundaria más o menos reciente que se ha venido produciendo acerca de su obra. Salvo error por mi parte, no ha sido nada o casi nada lo que se ha escrito sobre el sentido de la kidentificación" entre ser y lenguaje en Verdad y Método; y, en las escasas ocasiones en que se ha abordado este asunto, el propósito ha sido hasta ahora el de excluir precisamente el significado ontológico "fuerte» que me gustaría ahora realzar, apoyándome para ello en la tercera parte de Verdad y Método.

Como resulta patente, nos topamos aquí, de modo decisivo, con la cuestión de cuál es el significado global de la filosofía de Gadamer. Si nos atenemos a las lecturas pragmatistas más frecuentes, que tienden en general a subrayar el significado de la obra de Gadamer como un "renacimiento de la filosofía práctica", entonces esta obra -y por ende, la hermenéutica en general - habrá de pasar a la historia del pensamiento del siglo XX como una teoría, sin duda alguna significativa, centrada en la finitud y la historicidad de la comprensión: habrá sido ciertamente una obra decisiva a la hora de combatir las pretensiones de supremacía avanzadas por parte del cientificismo positivista; mas su marcada tendencia a quedarse en una predicación de cierta "sabiduría» no tendría sino un significado bien limitado para la ontología. Uno puede con razón argüir que tildar este resultado de fracaso, o siquiera considerarlo como un éxito de alcance redu- 
cido, implicaría la persistencia de un prejuicio metafísico con respecto a la ontología, prejuicio que la equipararía a una teoría sobre la naturaleza del ser, sobre su estructura necesaria, etcétera; mientras que lo propio de la hermenéutica es justamente el distanciarse frente a una ontología así entendida. La objeción, considerada desde el punto de vista del significado de la hermenéutica y de cómo esta transforma en sentido antimetafísico la concepción misma del ser, no alcanzaría en absoluto su propósito, pues.

Pero incluso una defensa similar del alcance ontológico de la hermenéutica obtiene validez tan sólo en la medida en que se sea consciente de que es esta una filosofía que ha eliminado los prejuicios metafísicos sobre la ontologia; y que por lo tanto ha transformado nuestra manera de pensar el ser, $y$ lo ha hecho antes ( $y$ con mayor profundidad) de haber sugerido cualesquier propuesta teórica o predicación moral basándose en la finitud y la historicidad de nuestra existencia. La insistencia en la coma de la frase a que hago referencia constituye precisamente el intento de comprender el sentido de esta transformación.

Una lectura atenta de la tercera parte de Verdad y Método demuestra que tal frase - recalcada, además, de manera muy especial por Gadamer, por cuanto la escribe en cursiva - no tiene tan sólo el sentido banal de identificar el campo de la comprensión con esta especie de ser que se nos presenta como lenguaje. De hecho, ¿de verdad sería posible extraer de esas páginas la tesis de que "hay» ser que no puede «ser comprendidow? Es decir, ¿que "hay" ser kantes» $y$ "fuera dew la comprensión? ¿Gadamer habría olvidado hasta ese punto la enseñanza de Heidegger y la noción misma de «diferencia ontológica»? Si hay un ser fuera de o antes de que venga al lenguaje, será necesario pensarlo como una presencia «objetiva» aún no "comprendida" en el horizonte del lenguaje. Pero precisamente el lenguaje es la (única) morada del ser. En fin, si no se planteasen estos interrogantes, podría considerarse como evidente el hecho de que la hermenéutica deja sin cuestionar el realismo ingenuo de la metafísica - realismo según el cual existe el mundo y existe el sujeto que lo observa, el cual pretende describirlo o apropiarse de él a través del «instrumenton del lenguaje-.

El hecho de que la frase sobre el ser-lenguaje constituya un problema para el traductor puede que nos revele algo: que Gadamer se interpretó a sí mismo en un sentido «realista»; en efecto, dado que Gadamer no explicita la interpretación ontológica radical —que nos parece la más coherente-, resulta fácil presumir 
que lo ocurrido es que no deseaba poner en cuestión las expectativas "realistas" de la conciencia «común». Habrá que estimar en este sentido, por ejemplo, algunas afirmaciones a simple vista marginales de Verdad y Metodo: como, por ejemplo, aquella con que finaliza el parágrafo sobre la «Rehabilitación de la autoridad y de la tradición ${ }^{6}$, donde Gadamer parece retomar, sin someterla a crítica alguna, la clásica distinción entre ciencias humanas y ciencias naturales, y donde afirma que, para estas últimas, «der Gegenstand [...] sich idealiter wohl bestimmen läßt als das, was in der vollendeten Naturerkenntnis erkannt wäre»" ${ }^{7}$. Estas páginas están incluidas dentro de un capítulo, «Erhebung der Geschichtlichkeit des Verstehens zum hermeneutischen Prinzip» ${ }^{8}$, que comienza con una discusión sobre la noción de círculo hermenéutico elaborada por Heidegger en Ser y Tiempo. En el parágrafo 32 de esta obra, precisamente, Heidegger refuta la idea de que la circularidad comprensión-interpretación se configure como un círculo vicioso (circulus vitiosus), círculo que condenaria al "ser ahí" a permanecer encerrado por siempre únicamente dentro de sus propios presupuestos privados:

Este círculo no debe rebajarse al nivel de un circulus vitiosus, ni siquiera tolerado. En él se alberga una positiva posibilidad de conocer en la forma más original, aunque una posibilidad que sólo es empuñada de un modo genuino cuando la interpretación ha comprendido que su primera, constante y última función es evitar que las ocurrencias y los conceptos populares le impongan en algún caso el «tener", el "ver" y el "concebir" "previos", para desenvolver estos partiendo de las cosas mismas, de suerte que quede asegurado el tema científico.?

${ }^{6}$ H.-G. GadAmer, Gesammelte Werke, I, op. cit., p. 281 ss. (VM, p. 344-353).

7 Versión española: «El objeto [de las ciencias naturales] puede determinarse idealiter como aquello que sería conocido en un conocimiento completo de la naturalezan; VM, p. 353. [Nota del traductor].

${ }^{8}$ Ibíd., p. 270 ss. (VM: «La historicidad de la comprensión como principio hermenéutico», p. 331-377).

9 M. HeIdegger, Sein und Zeit, Tubinga, Niemeyer, 1927 (versión española: El ser y el tiempo, trad. de J. Gaos, Barcelona, Planeta-De Agostini, 1993, p. 171-172; citamos, a partir de ahora, esta versión como ST). [Nota del traductor. El texto original alemán reza así: «Der Zirkel darf nicht zu einem vitiosum und sei es auch nur zu einem geduldeten herabgezogen werden. In ihm verbirgt sich eine positive Möglichkeit ursprünglichsten Erkennens, die freilich in echter Weise 
La precomprensión es la condición positiva de la interpretación, tanto para estas páginas de Ser y Tiempo como para Gadamer; el cual, como es sabido, piensa que "ein erster Sinn im Text [...] zeigt sich [...] nur, weil man den Text schon mit gewissen Erwartungen auf einen gewissen Sinn hin liest ${ }^{10}$. No se trata pues, de modo evidente (aunque no tan evidente para algunos intérpretes), de abordar un texto de una manera "neutral", a fin de conferirle un sentido después, interpretándolo. Pero, siendo esto así, ¿qué significaría, desde una perspectiva gadameriana, elaborar la precomprensión adecuada a partir de las cosas mismas? Nunca podrá esta precomprensión mostrarse "adecuada" a partir de una confrontación con el dato "objetivo" de la realidad misma del texto. Es de esta manera como Gadamer se embarcará entonces en la discusión del concepto de prejuicio y en la rehabilitación de los prejuicios «legítimos", los cuales identificará con aquellos presupuestos que no son solamente "privados" (así debe traducirse la palabra eigen, que frecuentemente acompaña en estas páginas a la palabra Vormeinungen $^{11}$ ), sino que nos son transmitidos por una tradición que les sirve, en cierto modo, de "verificación»" ${ }^{12}$. Lo clásico es precisamente el ejemplo de unos valores histórico-culturales que han superado este "test" y que, en consecuencia, se presentan ante nosotros con potestad normativa.

Más de uno, nos consta, ha vislumbrado en esta revalorización de la tradición contra la Ilustración (y también contra el historicismo romántico, por lo demás ${ }^{13}$ ) una caída inaceptable en el tradicionalismo que excluiría de la actividad hermenéutica "correcta» toda actitud crítica. Pero - aparte del hecho de que

nur dann ergriffen ist, wenn die Auslegung verstanden hat, daß ihre erste, ständige und letzte Aufgabe bleibt, sich jeweils Vorhabe, Vorsicht und Vorgriff nicht durch Einfälle und Volksbegriffe vorgeben zu lassen, sondern in deren Ausarbeitung aus den Sachen selbst her das wissenschaftliche Thema zu sichern"].

${ }^{10}$ H.-G. Gadamer, Gesammelte Werke, vol. I, op. cit., p. 271 (versión española: «En el texto un primer sentido [...] sólo se manifiesta porque ya uno lee el texto desde determinadas expectativas relacionadas a su vez con algún sentido determinado»; $V M$, p. 333).

${ }^{11}$ Ibíd., p. 273 (VM, p. 336). [Nota del traductor. Los traductores al castellano de Verdad y método I no acatan la sugerencia de traducción de Vattimo, y traducen eigen como "propias", de modo que el sintagma nominal completo "eigene Vormeinungen" queda recogido dentro de esta versión castellana, en páginas como la recién mentada, así: "propias opiniones previas»].

${ }^{12}$ Ibíd., p. 292 (VM, p. 356). [Nota del traductor. El alemán Bewährung, que Vattimo propone traducir como "verificación", es recogido por los traductores de la versión castellana de Verdad y método I como "confirmación"].

${ }^{13}$ Cf. ibíd., p. 276 ss. (VM, 338-344). 
Gadamer no está diseñando aquí una hermenéutica normativa, sino que más bien está describiendo fenomenológicamente lo que acaece ya siempre en todo acto interpretativo- es importante recordar que esta apelación a la tradición es inseparable de la constatación de su multiplicidad constitutiva:

Was unser geschichtliches Bewußtsein erfüllt, ist immer eine Vielzahl von Stimmen, in denen die Vergangenheit widerklingt. Nur in der Vielfachheit solcher Stimmen ist sie da. Das macht das Wesen der Überlieferung aus, an der wir teilhaben und teilgewinnen wollen. ${ }^{14}$

Yen fin:

Das Verstehen ist selber nicht so sehr als eine Handlung der Subjektivität zu denken, sondern, als Einrücken in ein Überlieferungsgeschehen, in dem sich Vergangenheit und Gegenwart beständig vermitteln. ${ }^{15}$

Sea cual sea la interpretación que le demos a estas afirmaciones, en todo caso es seguro que no hacen alusión alguna a una posible confrontación con una objetividad «exterion al texto. La alusión a las ciencias naturales a la que ya he hecho referencia, y que se encuentra precisamente en estas páginas, podría sin embargo sugerir, ciertamente, que aquí Gadamer estuviese hablando exclusivamente de las ciencias humanas. En cambio, considero significativo que aquellos intérpretes, como Grondin, que insisten en una lectura "realista" de la tesis ser-lenguaje recurran a citas que nada tienen que ver con las ciencias naturales. La búsqueda de la palabra justa - lo cual, según Grondin, debería demostrar que hay ser más allá del lenguaje-, ¿no será más bien equiparable a la labor de purificación de los prejuicios de la cual se habla en estas páginas sobre el círculo hermenéutico? Pero, tal y como resulta evidente si tomamos Verdad y Método en su con-

14 Ibld., p. 289 (versión española: «Lo que satisface a nuestra conciencia histórica es siempre una pluralidad de voces en las cuales resuena el pasado. Este sólo aparece en la multiplicidad de dichas voces: tal es la esencia de la tradición en la que participamos y en la que queremos participarw; $V M$, p. 353).

is Ibld., p. 295 (versión española: «El comprender debe pensarse menos como una acción de la subjetividad que como un desplezarse uno mismo hacia un aconsecer de la tradición, en el que el pasado y el presente se hallan en continua mediación; VM, p. 360). Las cursivas son de Gadamer. 
junto, esa purificación no significa en modo alguno que busquemos el adecuarnos al objeto, sino más bien que buscamos la inserción en la corriente viva de una tradición histórica, dentro de la cual nos encontramos ya siempre. Esta búsqueda tiene incluso el carácter de un diálogo: un diálogo que, contrariamente a lo que cree Grondin, no se limita a ser un diálogo consigo mismo. La tradición histórica es un diálogo real y concreto sea con las huellas heredadas del pasado, sea con los otros que nos son contemporáneos, tanto si pertenecen a nuestra cultura o proceden de otra. Posiblemente la búsqueda de la palabra justa resulte equiparable, en este caso, no solamente a la búsqueda de prejuicios legítimos, sino también al proceso de aplicación que Gadamer considera como paradigma de la actividad interpretativa. Pero ¿ «aplicarn querrá decir, aún aquí, el confrontar las palabras de la tradición con algo exterior? Resulta evidente que tampoco en este caso la confrontación implica, según Gadamer, un salto hacia afuera del lenguaje; sino que equivale más bien a la búsqueda de una adecuación que se «verifican en la medida en que se muestre coherente con (ciertas voces de) la tradición viva en que nos hallamos -es decir, no sólo en tanto en cuanto muestre su propia continuidad con tales voces, sino también por cuanto no clausure tal discurso, por cuanto lo predisponga a continuar ulteriormente-.

Todos estos «indicios" que permiten reconocer, no desde el ámbito de una metodología abstracta, sino desde la actividad interpretativa efectiva, los prejuicios legítimos, es decir, kadecuados” a las cosas mismas, ¿resultan en todo caso suficientes no sólo para suprimir las sospechas de tradicionalismo y de relativismo, sino también para justificar el propósito de una lectura ontológicamente radical de la tesis sobre el ser y el lenguaje? Planteo tal cuestión de manera bimembre dado que, en el desarrollo de estas observaciones, nos ha parecido que el urealismo* de Gadamer es consecuencia de su insistencia en el problema de la adecuación de la precomprensión: Gadamer habría excluido, en suma, el sentido ontológico radical de su tesis porque le habrían resultado inaceptables las consecuencias metodológicamente nihilistas de una identificación entre el ser y el lenguaje. La hipótesis que yo intento proponer, por el contrario, es que solamente una lectura ontológica radical de la tesis sobre el ser y el lenguaje nos permitirá suprimir cualquier sospecha de que la solución gadameriana al problema del círculo hermenéutico posea una salida relativista -0 , como mínimo, resulte vaga $\mathrm{e}$ insuficiente- Pues es justamente por no haber llevado hasta el final la identificación entre ser y lenguaje que Gadamer corre el riesgo de dejar sin responder la cuestión acerca de cómo son «testadosm los prejuicios legítimos. 
En las páginas antes citadas sobre el «descubrimiento heideggeriano de la precomprensión", Gadamer nos remite ${ }^{16}$ al parágrafo 63 de Ser y Tiempo, que entre otros hace referencia al "carácter metódico de la analítica existenciaria en general" y al "sentido del ser de la cura» (Seinssinn der Sorge) ${ }^{17}$. A propósito del carácter metódico de la analítica existencial, Heidegger formula de manera explícita la pregunta: «¿De dónde tomarán las proyecciones ontológicas la evidencia de la adecuación de sus 'descubrimientos' a los fenómenos?." ${ }^{18}$. Con el fin de responder a tal interrogante, Heidegger nos conduce de inmediato a la distinción entre existencia auténtica y existencia inauténtica: no es a partir de una u otra comparación entre la precomprensión y las cosas mismas de donde las proyecciones ontológicas obtendrán la evidencia de su adecuación con respecto a los fenómenos; sino que la obtendrán únicamente a partir de la autenticidad o inautenticidad de esas proyecciones como tales. Y, desde el momento en que se nos remite a considerar uno de los aspectos más radicales de la analítica existencial, la cuestión de la posibilidad de la existencia auténtica -la cual, como es sabido, sólo resulta posible si se basa en un anticipar o "precursar" la propia muerte-, el horizonte metodológico parece desmoronarse, dejado de lado. ¿Tiene ese desmoronamiento algo que ver con aquello que Gadamer denomina - mostrando mucha más «urbanidad» y, sin duda, refiriéndose al método de manera mucho más evidente- "Einrücken in ein Überlieferungsgeschehen» (la inserción en la corriente viva de una tradición histórica)? Cabe constatar ahí cierta conexión si se presta atención al hecho de que ambos caminos, tanto el de Gadamer como el de Heidegger, tienen en cuenta de forma explícita la historicidad del intérprete. Y no podemos en modo alguno ocultar que la tesis de Gadamer, que viene así a mostrarse como una lectura "urbanizada» del «ser para la muerte», acaba por desvelarnos el sentido de tal "ser" en una dimensión ajena, en cierta medida, al texto de Heidegger como tal. Lo que significa "anticipar» o "precursar» la muerte para Heidegger se capta más claramente, si bien de un modo existencial, en estas páginas

${ }^{16}$ Ibid., p. 274 (VM, p. 336).

${ }^{17}$ M. HeIDEgGer, Sein und Zeit, op. cit., p. 310 (ST, p. 338). [Nota del traductor. la expresión alemana que utiliza Heidegger en la versión original del primero de estos entrecomillados es "methodische Charakter der existenzialen Analytik überhaupt"].

${ }_{18}^{18}$ Ibíd., p. 312 (ST, p. 339). [Nota del traductor. la expresión alemana que utiliza Heidegger en la versión original es: "Woher sollen aber die ontologischen Entwürfe die Evidenz der phänomenalen Angemessenheit für ihre 'Befunde' nehmen?»]. 
de Gadamer. Hacerse cargo de la propia mortalidad significa precisamente insertarse en la corriente viva de una tradición histórica: es decir, hacerse cargo de forma radical de la propia historicidad. Y esto significa ante todo que la distinción que encontramos en Ser y Tiempo entre el pasado como vergangen (la relación inauténtica con la tradición) y el pasado como gewesen (donde éste se asume auténticamente como Überlieferung) se constituye al asumir el pasado no como un dato inmóvil, de hecho (la piedra del Es war que no puede ser volcada, y contra la cual se rebela el Zaratustra nietzscheano), sino más bien como un acontecimiento que sigue y seguirá engendrando nuevas posibilidades. Esta actitud «auténtica», si la pensamos en términos de cómo ha de ser nuestra relación con la tradición, significa que la herencia a la que acudimos para "testar" las precomprensiones, y reconocer entre ellas las que son legítimas, no es una estructura eterna del ser metafísico, sino simplemente una herencia histórica transmitida de unos mortales a otros mortales; es decir, se trata de un acontecimiento.

Pero, si nos quedásemos en este punto, resultaría difícil evitar una lectura de la hermenéutica gadameriana como mera filosofía de la finitud de los horizontes históricos, con los riesgos de relativismo que ello nos podría acarrear. Es verdad que Gadamer rechaza estos riesgos explícitamente cuando subraya que los horizontes históricos no están nunca cerrados sobre sí mismos, y que la fusión de horizontes es siempre, en último término, posible; con lo cual desaparece para él la idea de que tales horizontes puedan resultar al fin y al cabo intraducibles entre sí (idea que podría dar pábulo a la sospecha de relativismo). Pero probablemente resulta aún legítimo preguntarse hasta qué punto esta apertura indefinida se libra de reducir la historicidad a mera y simple finitud: pues tal reducción correría el riesgo de hacernos recaer en una metafísica existencialista. Si, en suma, el sentido global de la hermenéutica no es el de «descubrir un fundamento universalmente válido para la comprensión, a la manera del positivismo y de la metafísica, sino el de contribuir en la elaboración de una conciencia crítica de la finitud del Dasein al confrontar este último con las posibilidades que no pueden emanar sino de su situación concreta" ${ }^{19}$, entonces ese sentido acabará muy probablemente por reducirse únicamente a su aspecto negativo - es decir, a desechar las pretensiones de objetividad y de universalidad de la metafísica y del posi-

19 J. GRONDIN, L'universalité de l'herméneutique, op. cit., p. 159. 
tivismo-, sin ir mucho más lejos: quedándose, pues, en cierta prédica, muy vaga, de prudencia, de mesura, de tolerancia. Con lo cual, a pesar de todo el respeto que podamos sentir por tales valores y por la necesidad de fomentarlos en nuestras circunstancias actuales, quedaremos sin embargo insatisfechos por la vaguedad de conclusiones semejantes.

Podremos huir de pareja insatisfacción "desarrollandow las «claims» de Gadamer más allá de los resultados a los que él las ha llevado; pero permaneciendo fieles, con todo, a sus objetivos por cuanto proseguiremos ese diálogo crucial que el propio Gadamer ha mantenido desde siempre con Heidegger.

Se trata por consiguiente de retomar el discurso heideggeriano en torno a la autenticidad como única base posible de la adecuación de la precomprensión. Sólo bajo la luz de la proyección auténtica se mostrarán las cosas, pues, en lo que son verdaderamente, y no así en la inautenticidad del use dice» cotidiano, donde se nos muestran como meros entes "a la mano":

El absorberse en el uno significa la dominación del público "estado de interpretado». Lo descubierto y abierto se halla en el modo del «estado de desfigurado" y "estado de cerrado" por obra de las habladurías, la avidez de novedades y la ambigüedad. El user relativamente a los entes" no es extinto, pero sí arrancado a sus raíces. Los entes no son completamente ocultos, sino justamente descubiertos, pero al par desfigurados; se muestran — pero en el modo del "parecer..." ${ }^{20}$

Estos fragmentos deben leerse en relación con la última página de la primera sección de Ser y Tiempo, donde se dice: "Ser — no entes- sólo lo whay" hasta donde la verdad es. Y la verdad sólo es, hasta donde y mientras el Dasein es" (Sein — nicht Seiendes - "gibt es» nur, sofern Wahrheit ist. Und sie ist nur,

${ }^{20}$ M. HeIDEGGer, Sein und Zeit, op. cit., p. 222 (ST, p. 242-243). [Nota del traductor. la versión original alemana reza así: "Das Aufgehen im Man bedeutet die Herrschaft der öffentlichen Ausgelegtheit. Das Entdeckte und Erschlossene steht im Modus der Verstelltheit und Verschlossenheit durch das Gerede, die Neugier und die Zweideutigkeit. Das Sein zum Seienden ist nicht ausgelöscht, aber entwurzelt. Das Seiende ist nicht völlig verborgen, sondern gerade entdeckt, aber zugleich verstellt; es zeigt sich - aber im Modus des Scheinsw]. 
sofern und solange Dasein ist) ${ }^{21}$. El hecho de que el ser verdadero de las cosas se dé solamente en la existencia auténtica proviene de la definición misma que la analítica existencial ha dado de las cosas: estas son ante todo instrumentos, no objetos. Pero el ser del instrumento consiste en estar inserto dentro de una proyección: así se entiende por qué cuanto más explícitamente pertenezca la cosa a una proyección, más será. Y la proyección es je meine, siempre de alguien: cuanto más se la «apropie» un Dasein decidido (y, por lo tanto, abierto), más proyección será.

Sin embargo, todo esto no significa que el verdadero ser «en sín de la cosa se revele sólo en una proyección apropiada por un Dasein determinado, en cuyo caso la autenticidad de la existencia sería únicamente un instrumento adecuado para captar el ser como objetividad «puraw. Por el contrario, lo que se subraya insistentemente es que el ser no puede ser pensado como dato objetivo, independiente, de la cosa-objeto. ¿Estaremos tocando aquí la razón más íntima del paso de la Eigentlichtkeit al Ereignis en los textos de Heidegger? Porque el ser es acontecimiento - $\mathrm{y}$ no una estructura dada de una vez por todas, sino apertura $j e$ und $j$ e, que acontece cada vez-, ocurre que las cosas son solamente dentro de una proyección eigentlich. (El "porque» de la frase anterior no es sino una forma de hablar: no hay una estructura eventual del ser en sí - ni como su causa ni como su condición determinante- previa a la existencia en su posibilidad de autenticidad o inautenticidad...).

Parece que la preocupación -más propia de algunos intérpretes que del mismo Gadamer- de no reducir todo el ser al lenguaje responde a la intención de distinguir la verdad del ser con respecto a lo objetivo, en sí, independiente, falsificado y encubierto - claro está- por los excesos cientificistas de la metafísica y del positivismo; pero caracterizando todavía esa verdad como exterior y de alguna manera opuesta a la consciencia. Ahora bien, la única uobjetividad» del ser en la que se puede pensar, por el contrario, si se desea permanecer fiel a las premisas heideggerianas, es la que se impone al Dasein como su vocación y su

${ }^{21}$ Ibíd., p. 230 (ST, p. 251. [Nota del traductor, sólo eliminamos de esta cita en español del cuerpo del texto la idiosincrásica versión con que el traductor Gaos tradujo el término Dasein -esto es, el tecnicismo literalista y por él inventado, «ser ahím, para conservar, como viene haciendo Vattimo a lo largo de todo el articulo, la transposición del vocablo germano Dasein; y hacemos tal cosa con el fin de no denominar en esta traducción hispana de dos maneras distintas una misma noción]). 
herencia, como voz de lo otro que habla en la herencia histórico-cultural, en la Überlieferung, hacia la cual el Dasein auténticamente abierto se dirige, no como un contemplador pasivo, sino como proyección decisiva y decidida. El "verdadero" ser es el que se da al Dasein en esta relación de escucha-interpretación, no la cosa-misma que se presentaría en su inmediatez y para la cual el intérprete debería encontrar automáticamente la palabra adecuada.

Se debe por consiguiente leer la frase de Gadamer "Sein, das verstanden werden kann, ist Sprache» como una traducción, por así decirlo, de aquella otra de Ser y Tiempo: "Sein — nicht Seiendes_ "gibt es" nur, sofern Wahrheit ist. Und sie ist nur, sofern und solange Dasein ist». El ser es constitutivamente comprensibilidad y lenguaje porque no es Seiendes; porque, ante todo y de modo auténtico, no es ente. El nicht de la frase de Heidegger deber leerse en un sentido muy fuerte: no como una mera y simple aclaración léxica (hablamos aquí del ser y no del ente...), sino más bien como una indicación «teleológica», aunque no como la enunciación de un deber moral. Se trata de algo comparable a la diferencia entre autenticidad e inautenticidad de la existencia: para que se dé el ser, es en cierto modo preciso que el ente se niegue en su carácter de ente; es decir, en su realidad de la inmediatez cotidiana, que imagina el ente como un objeto dado en una esfera de neutralidad a la cual se le sobrepondrían en un segundo momento las proyecciones, igual que las palabras adecuadas que el intérprete trata de encontrar. El hallazgo de la palabra adecuada no pretende ser una «adecuación" a la objetividad cotidiana de la cosa; pretende sobre todo suprimir la cosa misma en su pretendida exterioridad, al conferirle un ser verdadero por su pertenencia a una proyección auténtica como inserción en la corriente viva de una tradición histórica. Tal inserción habría de compararse aquí con la forma en que John McDowell, desde una perspectiva postanalíti$\mathrm{ca}$, interpreta (equivocándose, aunque en mi opinión de una forma bien productiva) el a priori kantiano: la objetividad se produce, según él, por la aplicación al dato sensible de un sistema de categorías que se identifican con la red histórico-cultural de la racionalidad, es decir, del lenguaje heredado y compartido $^{22}$. Semejante referencia a Kant nos resulta con todo útil aquí por cuanto nos ayuda a esclarecer el papel que juega la distinción entre proyección autén-

22 Tales tesis las defiende el filósofo estadounidense en J. MCDOWELL, Mind and World, Cambridge, Harvard University Press, 1996 (versión española: J. MCDowell, Mente y mundo, trad. de M. A. Quintana Paz, Salamanca, Sígueme, 2003). [Nota del traductor]. 
tica-proyección inauténtica en la relación Kant-Heidegger. En cierta manera es cierto que para Heidegger no se da ningún a priori «estructural», «neutro»y que funcione de forma natural, sino que se dan únicamente proyecciones auténticas o inauténticas y, consiguientemente, aplicaciones por así decirlo "voluntarias" de dichas "categorías" particulares sobre los datos de la experiencia. Dicho más concretamente: el Dasein está ya siempre, desde el inicio y la mayoría de las veces, arrojado a una precomprensión inauténtica de las cosas como objetos, lo cual se puede comparar con la experiencia kantiana que se configura "naturalmente" según el a priori de la sensibilidad y el del entendimiento. Pero esta experiencia "natural», que toda perspectiva metafísica hasta la fenomenología ha considerado como norma y origen de verdad, está ya siempre (y, no obstante, históricamente) marcada por su sentido inauténtico: no da el ser verdadero, aun cuando se aluda a su insuficiencia, a su inestabilidad, a su carácter problemático y, por consiguiente, a la posibilidad auténtica. El ser adviene ante todo, precisamente, como apertura de esta posibilidad de la existencia auténtica, en la cual el Dasein aparece como agente y no solamente como espectador pasivo. La definición del Dasein en tanto que "un "poder ser" comprensor al que en su ser le va este mismo» (verstehendes Seinkönnen, dem es in solchem Sein um dieses als das eigene geht $)^{23}$ ha sido leída la mayor parte de las veces en un sentido primordialmente existencialista: como si el solches Sein fuera únicamente el ser del Dasein. Pero el Dasein existe en tanto que comprensión del ser, no solamente de su propio ser. Lo que está en juego, lo que concierne al Dasein, es el ser como tal.

El ser, claro está, y no el ente. Heidegger no está aquí formulando una ontología idealista: lo que "depende» del Dasein en su decisión por la autenticidad o la inautenticidad no es la realidad de las cosas en el espacio-tiempo. Esta realidad no es, de hecho, el verdadero ser de la cosa (véase sobre este tema todo el parágrafo 43 de Ser y Tiempo). El hecho de que la cosa, tal y como lo refleja el ensayo de tal título dentro de los Vorträge und Aufsätze ${ }^{24}$, sea propiamente no en el espacio-tiempo de la cotidianeidad, sino en el Geviert de cielo y tierra, mor-

${ }^{23}$ M. HeIDEGGER, Sein und Zeit, op. cit., p. 231 (ST, p. 253).

${ }^{24}$ M. HeIdEgGER, Vorträge und Aufsätze, Neske, Pfullingen, 1945 (versión española: M. HEIDEGGER, Conferencias y articulos, trad. de E. Barjau, Barcelona, Ediciones del Serbal, 2001). El "ensayo de tal título" al que se refiere Gianni Vattimo es el denominado "Das Ding" ("La cosa"). [Nota del traductor]. 
tales y divinos, este hecho no es simplemente una manera poética de hablar. «Voll Verdienst, doch dichterisch wohnet / der Mensch auf dieser Erden ${ }^{25}$; estos versos de Hölderlin, ampliamente comentados por Heidegger, significan también: resultaría desde luego realista pensar al hombre como un ser que comercia con los entes en el seno del mundo en tanto que objetos, res, realidades espacio-temporales; pero el hombre existe ante todo *poéticamente» - la autenticidad de su ser así como el ser de las cosas reside en el lenguaje en tanto que inserción en la corriente viva de una tradición histórica-.

¿Es posible conferir al doch de los versos de Hölderlin y al nicht de la frase de Ser y Tiempo («nicht Seiendes...») una significado fuerte, teleológico? A pesar de todas las afirmaciones en sentido contrario de Heidegger (y de Gadamer) - según las cuales no se trata aquí de nada que tenga que ver con tesis normativas o, para Gadamer, con prescripciones metodológicas-, no podemos reputar la distinción entre autenticidad e inautenticidad como una descripción uneutra", objetiva y aislada. El desarrollo del pensamiento heideggeriano hacia una consideración cada vez más explícita del ser como «historia» (Seinsgeschichte Seinsgeschick) parece apuntar a que tal pretensión de neutralidad se ha ido agotando progresivamente; e incluso a que es tal agotamiento el sentido mismo de la Kehre.

Dicho de manera aún más clara: si no es solamente descriptiva, la diferencia (ontológica, daro está) entre Seiendes y Sein implica incluso una tensión hacia la autenticidad, un esfuerzo hacia el ser. La «elaboración de una conciencia crítica del Dasein (Grondin) sólo puede significar esto, ya que, si no, no sería ni conciencia ni crítica. Buscar la autenticidad significa insertarse en la corriente viva de una tradición histórica, y por lo tanto explicitar (auslegen) la verdad del ser de la cosa no como objetividad neutra, sino como momento de un dis-cursus histórico al cual hemos sido arrojados; el Geviert, de igual manera, no significa sino eso mismo. ¿¿Supone esto que nos tengamos que referir en cada momento concreto solamente a nuestra situación histórica? Por ejemplo —como en el

25 Versión española: «Lleno de méritos, mas poéticamente habita el hombre sobre esta Tierra*. La mentada frase es comentada por Heidegger en pasajes como los pertenecientes a M. HEIDEGGER, Hölderlin und das Wesen der Dichtung, Múnich, Albert Langen-Georg Müller, 1937 (versión española: M. HeinegGer, Hölderlin y la esencia de la poesia, trad. de J. D. García Bacca, Barcelona, Anthropos, 1989). [Nota del traductor]. 
caso de la lectura relativista o tradicionalista del pensamiento de Gadamer-, ¿supone que tengamos que situar nuestras propias precomprensiones en el marco de la herencia manifiesta, de los clásicos, etcétera? La responsabilidad del filósofo no puede limitarse a enunciar el carácter «siempre y cada vez" arrojado de la existencia. Además, en tal caso semejante enunciación tendría la pretensión de no ser ella misma algo arrojado, por lo que resultaría aún deudora de la metafísica (o de la fenomenología), y no sería todavía hermenéutica. Hacerse auténticamente cargo de la historicidad significa también, y de manera ineludible, asumir la responsabilidad - en tanto que proveniente de y dirigida hacia alguna parte- de interpretar nuestro propio ser-arrojado. Sólo con una interpretación arriesgada y responsable como esta se puede evitar esa vaga insuficiencia que le reprochan algunos a la hermenéutica. No se es *auténtico" sólo con reconocer y teorizar la historicidad: hace falta asimismo decidirse por la posibilidad auténtica en una situación real. Ni Heidegger ni Gadamer ofrecen indicaciones explícitas sobre cómo alcanzar una decisión semejante. Cabe que Heidegger retrocediese ante tal labor debido a su *percance" nazi, que bien puede interpretarse como una comprensión errónea de sí mismo: un verdadero olvido de la diferencia ontológica, debido a su ilusión de poder reproducir, en un orden histórico determinado, cierta posibilidad de retorno a la autenticidad del ser. En el caso de Gadamer (y también, pero en otro plano, en el caso de Derrida, de quien no nos ocuparemos ahora), tal vez le afectó su preocupación por no recaer en una metafísica historicista: ni Gadamer ni Derrida hablan con agrado de «historia del ser». Pero es precisamente un residuo metafísico que ni uno ni otro se deciden a superar lo que le impide a Gadamer afirmar sin más que el ser, todo el ser, es lo que puede comprenderse como lenguaje. Este ser no se da en una descripción neutra, sino que adviene también sobre la base de la decisión auténtica del Dasein que va más allá de la «realidad" objetiva cotidiana. El kann de la frase de Gadamer es a la vez un darfy un soll, indica esa posibilidad auténtica que resuena en el nicht Seiendes de Sein und Zeit. Si para hacerse cargo efectivamente de la historicidad de nuestro ser-arrojado, si para insertarnos en la corriente viva - abierta, posible, a elegir - de una tradición histórica (en la historia del ser, no del ente-objeto) debemos correr el riesgo de establecer un hilo conductor en esta historia (no como dirección «objetiva" reconocida y aceptada de manera fatalista), entonces el único hilo al que podremos agarrarnos será el que la diferencia ontológica nos indica. Aquello a lo que nos llama la historia viva del ser en nuestra condición actual, es decir, la vocación del ser verdadero, es superar cada vez más decididamente lo "real» en la dirección del Ser - 
comprensión, lenguaje, "espíritu» en el sentido hegeliano-. El sentido ontológico de la hermenéutica no es entonces el de teorizar vagamente la finitud del Dasein mientras que se respetan los derechos de lo «real», sino el de poner en duda esos presuntos derechos y proponer una reconsideración radical de la noción misma de realidad. 